\title{
LETTER
}

\section{Glucose control in type 1 diabetes and COVID-19}

\author{
R. Mungmunpuntipantip ${ }^{1} \cdot$ V. Wiwanitkit ${ }^{2}$
}

Received: 6 September 2021 / Accepted: 6 October 2021 / Published online: 15 October 2021

(C) Italian Society of Endocrinology (SIE) 2021

Dear Editor,

We would like to share ideas on "Glucose control in homeisolated adults with type 1 diabetes affected by COVID-19 using continuous glucose monitoring [1]." Longo et al. concluded that "Young home-isolated patients with type 1 diabetes and COVID-19 showed a worsening of ...infection [1]." In general, COVID-19 can affect glucose metabolism and it might result in elevation of blood glucose and hemoglobin A1C [2]. If there is no good diabetic care during COVID19 illness, the DM patient under home isolation might have poor glucose control. In the present report, there are many confounding factors that might affect the observation on diabetic control. The severity of COVID-19 cases might be associated with outcome and there should be subgroup analysis. Additionally, medication used by patient should be mentioned. In our setting, Asia, many COVID-19 patients use alternative therapy and it can result in high blood glucose level. Furthermore, the use of telemedical care should be discussed. Whether the telemedicine care includes specific session on diabetic care is an interesting question.

\section{Declarations}

Conflict of interest The authors declare that they have no conflict of interest.

Research involving human participants and/or animals This study does not contain any studies with human participants or animals performed by any of the authors.

Informed consent For this type of study, formal consent is not required.

\section{References}

1. Longo M, Scappaticcio L, Petrizzo M, Castaldo F, Sarnataro A, Forestiere D, Caiazzo F, Bellastella G, Maiorino MI, Capuano A, Esposito K (2021) Glucose control in home-isolated adults with type 1 diabetes affected by COVID-19 using continuous glucose monitoring. J Endocrinol Invest. https://doi.org/10.1007/s40618021-01669-3 (Online ahead of print)

2. Sookaromdee P, Wiwanitkit V (2020) Estimated blood glucose and hemoglobin A1C in COVID-19: a preliminary summarization. Clin Lab. https://doi.org/10.7754/clin.lab.2020.200421

Publisher's Note Springer Nature remains neutral with regard to jurisdictional claims in published maps and institutional affiliations.

R. Mungmunpuntipantip

rujittika@gmail.com

1 Private Academic Consultant, Bangkok, Thailand

2 Dr DY Patil University, Pune, India 